\title{
Audit of emergency throughput of a plastic surgery unit in a developing country
}

Dear Sir,

Emergency service is an integral part of any discipline in clinical medicine, and it is considered as an indicator of the quality of health care system. ${ }^{[1]}$ This study was undertaken to assess the pattern and outcome of emergency surgical admissions to a plastic surgery unit with special emphasis on waiting period between admission and surgery.

Thirty-two patients admitted to the plastic surgery unit through emergency room of University of Ilorin Teaching Hospital between September 2005 and August 2007 were reviewed. Demographic information, diagnosis, interval between presentation and operative intervention; and management outcome were entered into a predesigned form.

Table 1 shows the demographic characteristics of the patients. There were 24 males and 8 females. The age range was 4 to 80 years, median being 31 years. The peak incidence was in the age group 21-40 years, accounting for $43.8 \%$ of all patients [Figure 1]. Twenty-eight $(87.5 \%)$ patients were admitted on account of trauma, and 4 (12.5\%) had infective causes. Most of the injuries encountered were avulsion injuries- $10(31.3 \%)$ patients, cuts and lacerations - 4 (12.5\%), crushed injuries- 4 (12.5\%), tendon injuries - 5 (15.5\%), fractured hand bones $3(9.4 \%)$, traumatic amputation of hand bones -2 $(6.3 \%)$, compartmental syndrome of the leg- 1 $(3.1 \%)$ and necrotizing fasciitis - $3(9.4 \%)$ patients. Road traffic injuries accounted for 14 injuries (9 motor vehicle and 5 motorcycle), industrial accident - 4 (12.5\%), infections - 4 (12.5\%) and matchet cuts- $3(9.4 \%)$; while 1 (3.1\%) patient each sustained injury from blast, traditional bonesetter splint and stab. Other mechanisms were involved in $4(12.5 \%)$ patients. Hand injuries accounted for $17(53.1 \%)$ admissions; there were 9 (28.1\%) 


\begin{tabular}{lcc}
\hline \multicolumn{3}{l}{ Table 1: Characteristics of the study population } \\
\hline Characteristic & \multicolumn{2}{c}{ Overall } \\
& $(n=32) \%$ & $\begin{array}{c}\text { Hand injury } \\
(n=17) \%\end{array}$ \\
\hline Peak age & $31-40$ years & $21-30$ years \\
Medial age & 31 years & 28 years \\
Sex ratio (M: F) & $3: 1$ & $15: 2$ \\
Medial injury arrival time & 4 hours & 3 hours \\
Injury-to-arrival & & \\
time (hours) & & \\
$<1$ & $6(18.8)$ & $5(29.4)$ \\
$1-6$ & $8(25)$ & $3(17.6)$ \\
$7-24$ & $6(18.8)$ & $4(23.5)$ \\
$25-72$ & $1(3.1)$ & - \\
$>72$ & $11(34.4)$ & $5(29.4)$ \\
Median delay between & 72 hours & 72 hours \\
admission and operation & & \\
\hline
\end{tabular}

leg injuries and $2(6.3 \%)$ head and neck injuries, while other body regions were injured in 4 (12.4\%) patients. Among the 17 patients with hand injuries, 13 injuries were right (dominant) sided, 3 were on the left side and 1 was bilateral. Road traffic injuries were responsible for hand injuries in 5 (29.4\%) patients; and operations of mechanical tools, in 4 $(23.5 \%)$ patients. Four patients each had tendon injuries and crush injuries; 3 each had avulsion injuries; and 2 each had traumatic amputations of the phalanges, fractures of metacarpals and others injuries. Most (5 [29.4\%]) of the patients with hand injuries were artisans (manual workers), followed by $4(23.5 \%)$ students, $2(11.8 \%)$ traders, $2(11.8 \%)$ farmers and 3 others. Fourteen (43.6\%) patients arrived within 6 hours of injury, and $62.4 \%$ of the patients arrived within 24 hours of injury. Three patients had their surgeries within 6 hours of presentation; 3 patients, between 6 and 24 hours of presentation; 6 patients, between 24 and 72 hours; and 20 patients had surgery after 72 hours of presentation. Median delay between presentation and surgery was 72 hours (range, 1-1440 hours). Tendon repair and Kirschsner wire insertion were done in 9 patients; debridement and subsequent split-thickness skin grafting, in 9; disarticulation and refashioning, in 2; and suturing was done in 5 patients.

Complications recorded included joint stiffness in 5 patients, wound infections in 4, hypertrophy scars in 3 , flap necrosis in 2 and stump necrosis in 2 patients. Mean duration of hospital stay was $37.7 \pm 31$ days, with a range of 1-116 days.

This study shows that trauma $(87.5 \%)$ is the leading cause of plastic surgery emergency admissions, and road traffic injury (44\%) is the leading cause of trauma. This is consistent with a previous report from this center, where trauma accounted for $70 \%$ of emergency admissions. ${ }^{[2]}$ The hand is more frequently injured than any other part of the body. This is because it is the

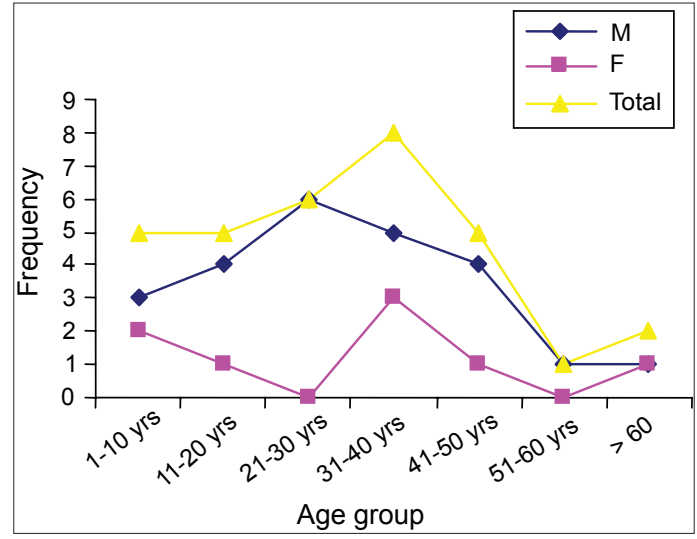

Figure 1: Age and sex distribution

means by which the environment is tested and manipulated, thereby increasing the risk of injury. Artisans were the people most vulnerable to hand injuries, which is in agreement with a previous report from Poland. ${ }^{[3]}$ Hand injuries in manual workers are frequently due to lack of compliance with the standard principles of work safety. The median delay between presentation and surgery of 72 hours is significantly longer than the mean of 1.3 to 16.9 hours reported in studies in developed countries. ${ }^{[3,4]}$ There is a need to evolve a policy that will improve this ugly situation. The reason for this delay was not obtained in this study but is not unrelated to ill-prepared emergency room, inadequate personnel, poor response time of the supporting departments like radiology and blood bank, inability of patients to finance treatment and non-availability of theater space as previously alluded in a report. ${ }^{[5]}$ The delay in surgical intervention leads to prolonged hospital stay and attendant loss of productive time of office and/or school for patients and caregivers. Cardinal to hand injury prevention is training in safety measures. Manual workers need to be educated and trained in workplace safety measures. This study emphasized the need to develop prompt emergency care services in the tropics to cater for the increasing trauma emergencies.

\section{Abdulrasheed A. Nasir, Ismaila A. Adigun, Adebiyi B. Aderibigbe, Oyekan 0. Folari}

\author{
Division of Plastic Surgery, Department of \\ Surgery, University of Ilorin Teaching Hospital, \\ llorin, Nigeria
}

Address for correspondence: Dr. A. A. Nasir, Department of Surgery, University of Ilorin Teaching Hospital, PMB 1459, llorin, Nigeria. E-mail:draanasir@yahoo.com

DOI: $10.4103 / 1596-3519.59587$ 


\section{References}

1. Saha S, Chandra S. Emergency otorhinolaryngological cases in medical college, Kolkata: A statistical analysis. Indian J Otolaryngol Head Neck 2005;57:219-25.

2. Solagberu BA, Adekanye AO, Ofoegbu CP, et al. Clinical spectrum of trauma at a university hospital in Nigeria. Eur J Trauma 2002;28:365-9.
3. Trybus M, Lorkowski ], Bronjel L, Hladki W. causes and consequences of hand injuries. Am J Surg 2006;192:52-7.

4. Nicholl ], Cole RP, Clarke JA. Audit of emergency throughput in a regional plastic surgery unit. Ann R Coll Surg Engl 1994;76:161-3.

5. Solagberu BA, Kuranga SA, Adekanye AO, et al. Preventable trauma deaths in a country without emergency medical services. Afr JTrauma 2003;1:39-44. 